\title{
Dos Posibles Direcciones De La Vivencia InTERrogativa ¿HAY ALGo? En EL Joven HeIDEgGer
}

\author{
Jorge Espinoza Cáceres ${ }^{l}$
}

\begin{abstract}
RESUMEN: El presente artículo pretende dos tareas: Primero, resaltar la vivencia cotidiana desde su inmediatez, y con ello, ganar su comprensión más propia a partir de la primera lección del joven Heidegger. Segundo, desde esta comprensión esclarecer lo que consideramos una confusa tematización de la vivencia interrogativa ¿hay algo? realizada en esta primera lección. Para ello consideramos necesario exponer en tres momentos distintos, la vivencia interrogativa; la vivencia circundante; y una comparación de los distintos elementos estructurales de ambas vivencias. Una vez comprendidos estos distintos puntos, proponemos en un último momento una interpretación de las dos posibles direcciones ejecutivas de la vivencia interrogativa ¿hay algo?
\end{abstract}

PALABRAS CLAVE: Joven Heidegger. Vivencia interrogativa. Vivencia circundante.

\section{INTRODUCCIÓN}

Hemos caminado en la aridez del desierto con la esperanza de comprender intuitivamente y de intuir comprensivamente en lugar de conocer siempre cosas... ${ }^{2}$

El siguiente escrito tiene como principal objetivo comprender el sentido de las vivencias según la primera lección de Freiburg del joven Heidegger titulada La idea de la filosofía y el problema de la concepción del mundo ${ }^{3}$. Significativa lección ya que en ella, por vez primera, Heidegger despliega una nueva y compleja posibilidad de tematizar, y con ello, de re-comprender el sentido

\footnotetext{
${ }^{1}$ Universidad Diego Portales, Instituto de Humanidades, Ejército 260, Santiago, Santiago, Chile. Email: morelli@ug.uchile.cl

2 "Wir sind in die Kümmerlichkeit der Wüste gegangen und harren darauf, statt ewig Sachen zu erkennen, zu schauend zu verstehen und verstehen zu schauen". HEIDEGGER, M. Zur Bestimmung der Philosophie, GA.56/57. 2. ed. Frankfurt a. M.: V. Klostermann, 1987, p. 65. Las citas de Heidegger contenidas en este artículo refieren a la Gesamtausgabe mediante las siglas GA, seguidas del número de volumen y página. Todas las traducciones de citas son del autor y van acompañadas en nota a pie del texto original. En caso de utilizar otras traducciones castellanas, el autor remite también a ellas.

${ }^{3}$ Die Idee der Philosophie und das Weltsanschauungproblem. En GA 56/57: Zur Bestimmung der Philosophie, editado por Bernd Heimbüchel. Frankfurt a. M.: Klostermann, 1999.
} 
de las vivencias. Consideramos decisivo destacar esta nueva posibilidad de tematizar las vivencias ya que a partir de este radical gesto emerge una nueva posibilidad de comprender el ejercicio filosófico, así como la emergencia de un nuevo "objeto" propio de la filosofía, que tanta resonancia tendrá en las corrientes filosóficas posteriores del siglo XX. La filosofía, según Heidegger, buscará acceder de manera transparente y coherente a la vida en sí, y con ello, o más bien por ello, exigirá la comprensión del sentido auténtico de las vivencias cotidianas desde su inmediatez más propia. Para concretar esta nueva posibilidad, Heidegger deberá rebasar una serie de distintos obstáculos. Entre ellos, el que consideramos en esta lección el más decisivo, a saber, la comprensión del sentido de la vivencia interrogativa ¿hay algo? y su compleja relación con la denominada esfera teorética. Este escrito requiere entonces - al igual que la propia lección del joven Heidegger - afrontar este obstáculo de la vivencia interrogativa, esto es, comprender su auténtico sentido, para con ello, aclararnos respecto del sentido de las vivencias en general. Pero según creemos, esta aclaración del sentido de la vivencia interrogativa ¿hay algo? no está exenta de oscuridades y complicaciones en la presente lección del joven Heidegger; antes bien, creemos reconocer en un primer acercamiento a esta enigmática vivencia interrogativa una serie de contradicciones y vacíos que reclaman ser atendidas para una comprensión más fecunda del sentido de las vivencias. Sostenemos entonces, que para acceder comprensiva y transparentemente al sentido de las vivencias circundantes tematizadas por el joven Heidegger, debemos a su vez, comprender el oscilante sentido de la vivencia interrogativa expuesto por Heidegger. Por ello, el siguiente escrito acomete dos tareas. Primero, resaltar la posibilidad de comprender y tematizar las vivencias en su inmediatez tratando de preservar su sentido inmediato. Cuya exposición estará compuesta en tres primeros momentos en donde desplegaremos el auténtico sentido de las vivencias circundantes en contraste con la vivencia interrogativa ¿hay algo? tematizada por Heidegger. Para, una vez desplegados los distintos elementos fundamentales propios de la caracterización de las vivencias circundantes y de la vivencia interrogativa ¿hay algo? ensayar en un cuarto y último momento dos posibles interpretaciones a propósito del sentido de la vivencia interrogativa ¿hay algo? conforme a dos distintas direcciones ejecutivas posibles: auténtica y des-vivificadamente. 


\section{BREVE CONTEXTUALIZACIÓN DE LA FORMULACIÓN DE LA VIVENCIA INTERROGATIVA ¿HAY ALGO?}

Recordamos brevemente al lector que la exposición de la vivencia interrogativa ¿hay algo? es formulada por el joven Heidegger a propósito de la determinación de la idea de la filosofía. El contexto es el siguiente: Heidegger al inicio de la lección pretende "ensayar" una idea muy particular de la filosofía, a saber, la idea de la filosofía como ciencia originaria. Lo que quiera decir esta idea al inicio de la lección es confuso e incierto. Lo que debemos hacer, decide Heidegger, es determinar la idea de la filosofía filosóficamente. Para ello Heidegger recurre al neokantismo de su época. Luego de una serie de rodeos confrontacionales con el neokantismo la discusión desemboca en el problema de la constitución del sujeto psíquico, en la determinación consistente de eso que se llama vivencia (Erlebnis). El problema en terminología neokantiana es el siguiente: si las vivencias psíquicas son el material al que se aplica la normatividad a priori ¿qué es propiamente el material, y cómo se constituye el sujeto psíquico? Es en este punto donde Heidegger traslada la discusión de la donación del sujeto psíquico hacia la pregunta por el ¿hay algo? Este brusco giro heideggeriano creemos pretende re-ensayar la pregunta por el sentido del ¿hay algo? desde una perspectiva que "rebase" el horizonte de determinación neokantiano. Volver un paso atrás, antes de la determinación del sujeto psíquico conforme a los planteamientos neokantianos hacia una nueva posibilidad de determinación. ¿Es esto posible? Leales al sentido general de esta lección, iniciamos nuestra exposición del sentido de las vivencias preguntando ¿hay algo.t

\section{A) LA VIVENCIA INTERROGATIVA ¿HAY ALGO?}

A propósito de esta interrogación Heidegger escribe al inicio de la segunda parte de la lección lo siguiente observación:

Nos hallamos ante la encrucijada metódica, que decide sobre la vida o la muerte de la filosofía en general, [nos hallamos] ante un abismo: o bien nos precipitamos en la nada, es decir, en la absoluta objetividad, o bien logramos el salto a un otro mundo, o más exacto: por primera vez a el mundo en general. ${ }^{5}$

\footnotetext{
${ }^{4}$ En el original: Gibt es etwas?

5 "Wir stehen an der methodischen Wegkreuzung, die über Leben oder Tod der Philosophie überhaupt entscheidet, an einem Abgrund: entweder ins Nichts, d.h. der absoluten Sachlichkeit, oder es gelingt der Sprung in eine andere Welt, oder genauer: überhaupt erst in die Welt." HEIDEGGER, M. Zur Bestimmung der Philosophie, GA.56/57. 2. ed. Frankfurt a. M.: V. Klostermann, 1987, p. 63.
} 
La reformulación de la pregunta por el ¿hay algo? según Heidegger nos permitiría acceder por vez primera al mundo en general, y con ello, a la determinación de la vida o muerte del propio ejercicio filosófico. ¿Cómo hemos de acceder a este nuevo y olvidado mundo? Heidegger afirma que el acceso a este nuevo mundo se juega en la posibilidad de comprender, de atender a sus auténticos motivos.

Queremos corresponder al simple sentido de la pregunta [hay algo] y comprender lo que ésta implica. Esto depende de escuchar los motivos que la alimentan. La pregunta es vivida. Yo vivo; yo vivo algo. Cuando nos entregamos lisa y llanamente a esta experiencia interrogativa, no reconocemos nada parecido a un pro-ceso o a un acontecer. [...] escuchar los motivos no significa buscar las causas (Ursachen) del devenir, las condiciones de objetivación; [tampoco significa] buscar las cosas que expliquen la vivencia como una cosa y en términos de cosas (Verdinglichtes), es decir, insertadas en un contexto de cosas. Debemos comprender los motivos puros del sentido de las vivencias puras. ${ }^{6}$

Detengámonos un momento en esta valiosa cita. En ella encontramos: i) La invitación por parte de Heidegger a escuchar los verdaderos motivos de la vivencia interrogativa. ii) La sutil pero determinante afirmación acerca de la "naturaleza" de la vivencia interrogativa - que después va a hacer extendida a toda vivencia en general - a saber, la vivencia no es ni pro-ceso (Vor-gang), ni tampoco un acontecer (Geschehen) iii) Escuchar los motivos no es objetivizar las vivencias, entenderla como una cosa entre un contexto de otras cosas - clara referencia a la encrucijada vital de la filosofía. Preguntamos entonces ¿en qué consiste según Heidegger, este auténtico sentido? Después de un par de rodeos, de falsos senderos, Heidegger nos delimita el camino: "No se pregunta, si algo se mueve, si algo está en reposo, si algo se contradice, si algo actúa, si algo existe, si algo vale, si algo debe ser, sino si hay algo. ¿Qué significa: "hay"?”7 El camino se perfila, debemos comprender "sencillamente" el significado del hay. Preguntamos entonces:

\footnotetext{
6"Wir Wollen dem schlichten Sinn der Frage entsprechen, das, was in ihr liegt, verstehen. Es kommt darauf an, die Motive heruaszuhören, aus denen sie lebt. Die Frage ist erlebt. Ich erlebe. Ich erlebe etwas. Wenn wir uns schlicht hingebend diesem Frageerlebnis gegenüber verhalten, erkenne wir nichts von einem Vor-gang, einem Geschehen [...] Motive heraushören besagt nicht, nach Ursachen des Entstehens, nach Be-dingungen, Dingen suchen, die das Erlebnis als Ding und Verdinglichtes erklären, d.h. in einen Sachzusammenhang hineinstellen. Verstehen sollen wir die reinen Motive des Sinnes des reinen Erlebnisses." HEIDEGGER, M. Zur Bestimmung der Philosophie, GA.56/57. 2. ed. Frankfurt a. M.: V. Klostermann, 1987, p. 65-66.
}

7 "Nicht is gefragt, ob sich etwas bewegt, ob etwas ruht, ob etwas sich widerspricht, ob etwas wirkt, ob etwas existiert, ob etwas werter, ob etwas soll, sondern ob es etwas gibt. Was heißt: 'es gibt'?" HEI- 
¿qué significa hay? Por lo pronto, sabemos según Heidegger sólo lo negativo, lo que no es: no es ni un pro-ceso ni un acontecer, ni una objetivación de las vivencias. No podemos aún asir su sentido. Y creemos topar con este problema precisamente porque todo es susceptible de caer en el hay algo, o mejor dicho, nada en particular agota el sentido propio de la pregunta ¿hay algo? Podemos decir con sentido que hay árboles, hay poemas, hay poetas, pero que también hay valores, hay ideas, hay números; al parecer, todo es aludido cuando preguntamos por ¿hay algo? Pero, al igual que ningún ente en particular agota el sentido de la interrogación ¿hay algo? debemos reparar también que su sentido tampoco apela a nuestra existencia en particular, es decir, nuestra propia situación particular no es aludida por la pregunta ¿̨hay algo? Heidegger precisa:

¿Se da en ella [ésta vivencia interrogativa en particular] algo así como la significativa remisión a mí, al que está aquí en la cátedra, con este nombre y esta edad? [...] Evidentemente no. De este modo: inmediatamente no sólo no se aprehende un yo [...] se ve, que el sentido de la vivencia no tiene ninguna relación con un yo particular. ${ }^{8}$

No somos aludidos por la vivencia interrogativa ¿hay algo? según Heidegger. No somos nosotros para quien ni hacia quien se dirige el sentido de la pregunta. Al sentido propio de esta pregunta, no le "interesa" nuestra finita existencia. Puede ser formulada por mí, por algún amigo, o por algún desconocido y sin embargo, pese a los distintos interrogadores la pregunta sigue inalterada, su ambiguo sentido persiste y se resiste a nuestra propia existencia. En la comprensión de esta interrogante no está en juego nuestro "yo" particular. Nuestra existencia en particular, nuestro yo-singular no es alcanzado por esta interrogante. Heidegger además señala que:

La pregunta es si hay en general un objeto ahí. La vivencia no es una cosa, que exista en bruto, que empiece y acabe como un pro-ceso [Vor-gang] [...] En principio, el carácter no cósico de la vivencia y de cada vivencia

DEGGER, M. Zur Bestimmung der Philosophie, GA.56/57. 2. ed. Frankfurt a. M.: V. Klostermann, 1987, p. 67.

8 "Gibt sich in ihm so etwas wie die sinnhafte Zurückverweisung auf mich, der hier am Katheder steht, mit diesem Namen und diesem Alter? [...] Offenbar nicht. Also: Unmittelbar ist nicht nur nicht ein Ich zu erfassen [...] zeigt es sich, daß der Sinn des Erlebnisses auf die einzelnen Ich keinen Bezug hat". HEIDEGGER, M. Zur Bestimmung der Philosophie, GA.56/57. 2. ed. Frankfurt a. M.: V. Klostermann, 1987, p. 68. 
en general se deja comprender absoluta e intuitivamente a partir de esta vivencia en particular. ${ }^{9}$

De acuerdo a esta cita, a partir del análisis exhaustivo del auténtico sentido de esta vivencia interrogativa estaríamos en condiciones para comprender "plena e intuitivamente" el carácter no cósico de toda vivencia en general. Es decir, el análisis del sentido la vivencia interrogativa pretende sencillamente mostrar que las vivencias interrogativas - incluso esta vivencia interrogativa tan peculiar y abstracta - no pueden ser reducidas o comprendidas en tanto cosas, como resultados de un pro-ceso. Pero en ningún modo estamos en condiciones para i) comprender la relación entre el sentido de la vivencia interrogativa ¿hay algo? y toda vivencia interrogativa, ni menos aún la relación entre esta vivencia en particular y toda vivencia en general. ii) Así como tampoco estamos en condiciones de determinar la estructura interna de esta vivencia interrogativa en particular. Por el momento sólo sabemos que los atributos propios del sentido de esta interrogación son negativas, es decir, sólo sabemos que no es una cosa, ni un pro-ceso, ni un acontecer, además de que no somos particularmente aludidos por ella. ¿Con qué nos quedamos si sólo sabemos lo que esta vivencia interrogativa no es?

\section{B) LA VIVENCIA CIRCUMUNDANA (UMWELTERLEBNIS).}

Ante esta dificulta Heidegger despliega una nueva estrategia para poder asir el sentido de esta vivencia interrogativa. Ensaya el análisis de una nueva vivencia, a saber, la vivencia del ver la cátedra:

Yo voy a evocar una nueva vivencia, no solo para mí mismo, sino que les pido a todos ustedes, a cada yo-mismo singular, sentado aquí, que hagan lo mismo [...] Ustedes entran como de costumbre en esta aula a la hora acostumbrada y van a $s u$ acostumbrado puesto. Retengan firmemente esta vivencia de "ver su puesto" o pueden ustedes incluso realizar mi propia situación: entro en el aula y veo la cátedra [...] Veo la cátedra de golpe, y no la veo aislada; veo el pupitre como demasiado alto para mí. Veo un libro que está encima, lo veo inmediatamente como estorbándome (un libro, y

\footnotetext{
9 "Es ist de Frage, ob überhaupt ein Objetkt da ist. Das Er-leben ist keine Sache, die brutal existiert, anfängt und aufhört wie ein Vor-gang [...] Die Nicht-Sachartigkeit des Erlebnisses und jedes Erlebnisses überhaupt ließe sich prinzipiell schon an diesem einzigen Erlebnis zum absoluten, schauenden Verständnis bringen.” HEIDEGGER, M. Zur Bestimmung der Philosophie, GA.56/57. 2. ed. Frankfurt a. M.: V. Klostermann, 1987, p. 69.
} 
no un cierto número de hojas, guarnecido con pastas negras), veo la cátedra en una orientación, en una iluminación, en un trasfondo. ${ }^{10}$

¿Qué nuevas características reconocemos en esta otra vivencia? Si escuchamos ahora los motivos que alimentan a esta vivencia del ver la cátedra podemos reconocer, por lo pronto, la siguiente primera característica: La significativa inmediatez de lo vivido. Al entrar en la cátedra, al ver la cátedra, la reconozco inmediatamente dotada de sentido, ella significa inmediatamente para mí. Puede significar el lugar en donde actualmente estoy tratando de aprender algo acerca del ejercicio filosófico, o el lugar donde justamente no encuentre indicios de filosofía, o sencillamente un lugar en donde me encuentro con amigos, etc. Las características atribuidas a Heidegger a esta experiencia son: "veo el pupitre demasiado alta para mí, veo la cátedra en una cierta orientación". Lo decisivo es la inmediatez significativa de la cátedra. "La veo de golpe", dice Heidegger. Lo vivido, lo experimentado, lo comprendo inmediatamente dotado de sentido. Lo que sucede inmediatamente en la vivencia del ver la cátedra es su comprensión significativa en algún respecto.

Este primer elemento estructural del ver la cátedra pretende ir más allá de esta peculiar vivencia del ver la cátedra. De acuerdo a Heidegger, la inmediatez significativa no es algo contingente a ésta vivencia en particular y no perteneciente a otras vivencias; todo lo contrario, esta caracterización de la inmediatez significativa pretende ser una característica estructural de toda vivencia circumundana. ¿Cómo es esto posible; y qué quiere decir vivencia circumundana? Retomemos la lección del joven Heidegger y la variación o “ampliación” de la vivencia del ver la cátedra. Heidegger escribe:

Pero imaginemos que de repente sacamos a un negro senegalés de su cabańa y que lo colocamos aquí. Resulta difícil precisar con exactitud lo que vería al fijar la mirada en este objeto. Quizás viera algo relacionado con la magia o algo que sirve para protegerse de las flechas y piedras. Pero lo más probable es que no supiera qué hacer con esto. ¿Acaso vería simples

\footnotetext{
10 "Ich bringe mir selbst nicht nur für mich ein neues Erlebnis zur Gegebenheit, sondern bitte Sie alle, jedes vereinzelte Ich-Selbst, das hiers sitzt, dasselbe zu tun [...] Sie kommen wie gewöhnlich in diesen Hörsaal um die gewohnte Stunde und gehen auf Ihren gewohnten Platz zu. Dieses Erlebnis des 'Sehens Ihres Platzes' halten Sie fest, oder Sie können meine eigene Einstellung ebenfalls vollziehen: In den Hörsaal tretend, sehe ich das Katheder [...] Ich sehe das Katheder gleichsam in einem Schalg; ich sehe es nicht nur isoliert, ich sehe das Pult als für mich zu hoch gestellt. Ich sehe ein Buch darauf liegend, unmittelbar als mich störend (ein Buch, nicht etwa eine Anzahl geschichteter Blätter mit schwarzen Flecken bestreut), ich sehe das Katheder in einer Orientiergung, Beleuchtung, einem Hintergrund." HEIDEGGER, M. Zur Bestimmung der Philosophie, GA.56/57. 2. ed. Frankfurt a. M.: V. Klostermann, 1987, p. 70-71.
} 
complejos de colores y superficies, una mera cosa, algo que simplemente se da? ${ }^{11}$

No. Heidegger sostiene que sea lo que fuera que viera el negro senegalés necesariamente sería algo unido a un momento significativo, esto es, algo inmediatamente significando. Por ello concluye que:

Este mundo (la cátedra, el libro, la pizarra, el cuaderno de apuntes, la estilográfica, el bedel, la asociación de estudiantes, el tranvía, el automóvil, etc.) no consta de cosas con una determinada característica de significación, de objetos a los que además se añada el que hayan de significar esto y lo otro, sino que lo significativo es lo primario, se me da inmediatamente, sin ningún rodeo intelectual que pase por la captación de una cosa. Viviendo en un mundo circundante, me encuentro rodeado siempre y por doquier de significados, todo es mundano, "mundea. ${ }^{12}$

Lo decisivo es que las vivencias circumundanas están constituidas por la significatividad inmediata. Lo vivido, las experiencias-vivencias son ante todos "cosas" dotadas de sentido, significados inmediatamente comprendidos. Esta es justamente la primera de las características estructurales reconocidas por el joven Heidegger inherentes a las vivencias circumundanas: el mundear o la inmediatez significativa ${ }^{13}$. Ahora bien, hemos dicho - en consonancia con Heidegger - que el mundear es la primera de las características de las viven-

11 "Aber denken wir uns einen Senegalneger als plötzlich aus seiner Hütte hier herein verpflanzt. Was er, diesen Gegenstand anstarrend, sähe, wird im einzelnen schwer zu sagen sein, vielleicht etwas, was mit Zauberei zu tun hat, oder etwas, hinter dem man guten Schutz gegen Pfeile und Steinwürfe fände, oder aber, was das Wahrscheinlichste ist, er wüßte damit nichts anzufangen, also er sähe bloß Farbenkomplexe und Flächen, eine bloße Sache, ein Etwas, das es einfachhin gibt?” HEIDEGGER, M. Zur Bestimmung der Philosophie, GA.56/57. 2. ed. Frankfurt a. M.: V. Klostermann, 1987, p. 71-72.

12 "Dieses Umwelthliche (Katheder, Buch, Tafel, Kollegheft, Füllfeder, Pedell, Korpsstudente, Straßenbahn, Automobil usf. usf) sind nicht Sache mit einem bestimmten Bedeutungscharakter, Gegestände, und dazu noch aufgefaßt als das und das bedeutend, sondern das Bedeutsame ist das Primäre, gibt sich mir unmittelbar, ohne jeden gedaklichen Umweg über ein Sacherfassen. In einer Umwelt lebend, bedeutet es mir überall un immer, es ist alles welthaft, 'es weltet'" HEIDEGGER, M. Zur Bestimmung der Philosophie, GA.56/57. 2. ed. Frankfurt a. M.: V. Klostermann, 1987, p. 72-73.

${ }^{13}$ Confróntese la siguiente aclaración de Ramón Rodríguez a propósito del mundear de las vivencias circundantes: "[...] esta primacía absoluta de las cosas-sentido permite a Heidegger rechazar como infundadas $[\ldots]$ todas las teorías que hacen de la significatividad un añadido, por muy esencial que sea, a la cosa. [Ya que] para entender la significación como un añadido, la cosa como una síntesis de materia amorfa y significado, tenemos que pensar un momento de materialidad pura, de asignificatividad previa a la significación...” RODRÍGUEZ, R. La transformación hermenéutica de la fenomenología. Madrid: Tecnos, 1997, p. 27. 
cias circumundanas. Pero ¿`reconocemos esta característica en la vivencia de la interrogación hay algo? ¿En ella se mundea? ¿Podemos equiparar la vivencia interrogativa ¿hay algo? con la vivencia del ver la cátedra? ¿Es acaso la vivencia interrogativa una vivencia circumundana? ¿Y si no lo es, qué clase de vivencia es? Es necesario retomar el análisis de la vivencia interrogativa del ¿hay algo? y contrastarla con la vivencia circumundana del ver la cátedra.

\section{C) COMPARACIÓN DE LAS ESTRUCTURAS DE LAS VIVENCIAS ANTERIORMENTE ANALIZADAS}

Sólo en la consonancia del yo propio respectivo se vive lo circundante, mundanea, y allí donde y cuando mundanea para mí, estoy yo de alguna forma totalmente allí. Pongamos al lado (mantengamos) la vivencia interrogativa. En ella no me encuentro yo mismo. El algo, por cuyo 'hay» se pregunta, no mundea. Lo mundanal está aquí apagado, captamos toda posible cosa circundante como un algo en general. Este captar, este establecer algo como objeto en general, vive a costa de la represión de mi propio yo. El estar frente [Gegenstand] a mí, el ser objeto [Objektsein] no me afecta. El yo que establece ya no soy yo. El establecer [Feststellen] es, como vivencia, sólo un rudimento de vivencia; es un des-vivir. Lo objetivo, lo conocido es, como tal, alejado, sacado de la auténtica vivencia. El acontecer objetivado [Das objektivierte Geschehen], el acontecer en cuanto objetivo [das Geschehen als gegenständliches], conocido, lo designamos pro-ceso (Vor-gang); pasa simplemente por delante de mí yo cognoscente, con el que sólo tiene la relación de ser conocido, esa relación con un yo vaciada, reducida a un mínimo de vivencia [...] En el comportamiento teorético me dirijo hacia algo, pero yo no vivo (en cuanto yo histórico) en contacto con este o aquel [elemento] mundanal. ${ }^{14}$

\footnotetext{
${ }_{14}$ "Nur in dem Mitanklingen des jeweiligen eigenen Ich erlebt es ein Umweltliches, weltet es, und wo und wenn es für mich weltet, bin ich irgendwie ganz dabei. Halten wir daneben das Frageerlebnis. Darin finde ich mich selbst nicht vor. Das Etwas überhaupt, nach dessen 'es geben' gefragt ist, weltet nicht. Das welthafte is hier ausgelöscht, fassen wir jedes mögliche Umweltliche als Etwas überhaupt. Dieses Fassen, Fest-stellen als Gegenstand überhaupt, lebt auf Kosten der Zurückdrängung meines eigenen Ichs. Es liegt im Sinne des Etwas überhaupt, daß ich nicht in der Fest-stellung seiner als solchen mitschwinge, sondern dieses Mitschwingen, dieses Mitherausgehen meiner ist unterbunden. Das Gegenstand-, das Objektsein als solches berührt mich nicht. Das Ich, das fest-stellt, bin ich gar nicht mehr. Das Festellen als Erlebnis ist nur noch ein Rudiment von Er-leben; es ist ein Ent-leben. Das Gegenständlichen, das Er-kannte, ist als solches ent-fernt, aus dem eigentlichen Erleben herausgehoben. Das objektivierte Geschehen, das Geschehen als gegenständsliches, erkanntes, bezeichnen wir als Vor-gang; es geht schlicht vor-bei, vor meinem erkennenden Ich, hat zu diesem nur den Bezug der Erkanntseins, diese abgeblaßte, auf ein Minimun von Erleben reduzierte Ichbezogenheit [...] Im theoretischen Verhalten bin ich gerichtet auf etwas, aber ich lebe nicht (als historisches Ich) auf dieses oder jenes Welthafte zu." HEIDEGGER, M. Zur Bestimmung der Philosophie, GA.56/57. 2. ed. Frankfurt a. M.: V. Klostermann, 1987, p. 73-74.
} 
Esta larga cita nos aporta valioso material de análisis para comprender la estructura de la vivencia circumundana y compararla con la vivencia interrogativa. Para ello, examinemos primero los elementos estructurales referidos a la vivencia circumundana contenidos en la cita anterior, para luego concentrarnos en la vivencia interrogativa. El primero de los elementos que encontramos - y que no vamos a volver a caracterizar - es el ya caracterizado carácter significativo de las vivencias, esto es, el mundear de las vivencias circumundanas; pero ahora al mundear se ańade un nuevo elemento estructural, a saber, el yo-histórico.

El yo-histórico. Este nuevo elemento estructural hace referencia a la finitud inigualable de cada yo singular que vive y encarna toda vivencia circumundana. ¿Pero, por qué histórico? A nuestro entender Heidegger caracteriza al yo en tanto histórico porque este rasgo resalta el carácter único, irrepetible, propio de cada existencia individual-finita, prescindiendo, o superando si se prefiere, las típicas caracterizaciones físico-psíquicas de los individuos. Mi yohistórico es inconfundible y nunca imitable en comparación a cualquier otro yo-singular. Ramón Rodríguez a propósito de este elemento estructural de las vivencias circumundanas comenta lo siguiente:

No son características psicológicas personales, intercambiables con individuos del mismo tipo psíquico, lo que distingue al yo, sino tener una historia; un ser que se hace en una situación dada, que se gesta constantemente, no puede propiamente ser tipificado; su proceso de gestación es literalmente único. ${ }^{15}$

Tenemos por el momento que la estructura relativa a toda vivencia circumundana está compuesta por: i) la significatividad inmediata, o lo que Heidegger ha caracterizado como el mundear; y ii) la participación del yo-histórico. Pero, ¿qué sucede con el sentido de la vivencia interrogativa ¿hay algo? que anteriormente hemos abandonado? Consideremos ahora nuevamente su sentido a la luz de estas nuevas caracterizaciones de la vivencia circumundana. En la extensa cita anterior se añaden, a nuestro entender, dos nuevas precisiones para comprender la vivencia interrogativa, a saber, la des-vivificación y la "ausencia" del yo histórico, además del esclarecimiento de la enigmática caracterización anteriormente señalada: ser pro-ceso. La "ausencia" del yo es algo que anteriormente había sido formulado en la comprensión del sentido de la vivencia interrogativa, pero en la forma de un no ser aludido nuestro yo-parti-

${ }^{15}$ RODRIGUEZ, R. La transformación hermenéutica de la fenomenología. Madrid: Tecnos, 1997, p. 28. 
cular. Lo que se ańade ahora, es que este yo, no sólo no es aludido, sino que la propia consideración de las cosas en tanto objetos exige que el yo que establece esta consideración en términos de objetos ya no soy yo; al contrario, este yo que establece es sólo un rudimento de mi yo-histórico, un residuo de mí existencia particular. Y conforme a este residuo de mi yo-histórico, la vivencia que establece lo vivido en tanto cosas, no es ella misma una autentica vivencia, sino a su vez, un residuo de una auténtica vivencia, esto es, una des-vivificación de la auténtica vivencia. Comprendemos ahora a lo que se refería enigmáticamente Heidegger como un pro-ceso, esto es, a un acontecer objetivador, en donde la vivencia genuina ha sido des-vivificada - " El acontecer objetivado [Das objektivierte Geschehen], el acontecer en cuanto objetivo [das Geschehen als gegenständliches], conocido, lo designamos suceso (Vor-gang)" Pero, ¡cómo puede ser la vivencia interrogativa un pro-ceso si establecimos en el primer análisis de la vivencia interrogativa, en la comprensión de su auténtico sentido que ella misma no era un pro-ceso - "cuando nos entregamos lisa y llanamente a esta experiencia interrogativa, no reconocemos nada parecido a un pro-ceso o a un acontecer." - sino algo otro?

\section{D) Dos POSIBLES DESPLIEgUeS EJECUTIVOS DE LA VIVENCIA INTERROGATIVA ¿HAY ALGO?}

He aquí una posible interpretación a propósito del sentido de la vivencia interrogativa: dos posibles sentidos del ¿hay algo? Consideramos que esta contradictoria consideración puede ser salvada si entendemos que el análisis de Heidegger contenido en el pasaje anterior tiene a la vista la vivencia interrogativa a la luz de su génesis investigativa, a saber, como interrogación a propósito de la posibilidad de la donación material del sujeto psíquico en el horizonte neokantiano de determinación. Si recordamos que la formulación de la vivencia interrogativa ¿hay algo? emerge en la lección del joven Heidegger en el contexto teórico neokantiano justamente a propósito de la posibilidad de determinar la donación del sujeto material - o si se prefiere la constitución del sujeto psíquico - y su relación con las estructuras de valor, de verdad, etc., esto es, respecto a su normatividad a priori $^{16}$. Vemos que la vivencia interrogativa ¿hay algo? está ella misma ya constreñida, comprendida a partir de una formulación totalmente teorética. Sostenemos entonces que Heidegger, en la extensa

${ }^{16}$ Cf. HEIDEGGER, M. Zur Bestimmung der Philosophie, GA.56/57. 2. ed. Frankfurt a. M.: V. Klostermann, 1987, p. 29-62. 
cita anterior, tiene precisamente a la vista esta dirección ejecutiva de la vivencia interrogativa, es decir, justamente como una vivencia derivada, brutalmente teorizada, esto es, como un pro-ceso, como una des-vivificación de la vivencia auténtica y como residuo de mi yo-histórico. Creemos que justamente con esta consideración a la vista de la vivencia Heidegger escribe que: "la vivencia interrogativa '‘hay algo?', se nos mostró su contenido tras adoptar un contexto objetivo único y exclusivo como existente (absolutización de la cosidad)”17 Pero, gracias a que las vivencias tienen estos dos "polos extremos" - auténtica o des-vivificada - podemos "rastrear" los auténticos motivos de esta pregunta, podemos situarnos auténticamente en esta vivencia interrogativa, reincorporarla en su sentido inmediato, en sus auténticos motivos, desatendiendo su impuesta formulación teorética como la posibilidad de la donación material del sujeto psíquico. Sostenemos en definitiva que el análisis heideggeriano de la vivencia interrogativa ¿hay algo? oscila unas veces como una vivencia desvivificada, esto es, como un pro-ceso, y otras veces como una vivencia auténticamente ejecutada. Consideramos iluminador que Heidegger tenga algunas veces a la vista la posibilidad de ejecutar la vivencia interrogativa a partir de su vertiente auténtica, desde su coherente sentido, en donde justamente la vivencia ¿hay algo? puede ser comprendida no como pro-ceso, ni como acontecer objetivante. ${ }^{18}$ Aunque Heidegger no establezca claramente estas dos direcciones ejecutivas de la vivencia interrogativa, creemos - como interpretación factible - que ambas posibilidades ejecutivas están operando por momentos alternadamente en los análisis de Heidegger. Y de acuerdo a estas consideraciones, sostenemos que la caracterización de la vivencia interrogativa contenida en la siguiente cita: "en el ver de la catedra estoy plenamente presente con mi yo [...] no se trata [entonces] de un pro-ceso, sino de una apropiación (un noproceso, en la vivencia interrogativa un residuo de esta apropiación)" ${ }^{19}$ puede no sólo calzar armónicamente con todos los análisis previamente expuestos, sino además aportar nuevos y valiosos elementos para la comprensión del

\footnotetext{
17 “[...] das Frageerlebnis 'Gibt et etwas?' ergab sich uns seinem Gehalt nach aus dem Verfolg der Annahme eines einzigen und ausschließlichen Sachzusammenhags als existentem (Verabsolutierung der Sachartigkeit)." HEIDEGGER, M. Zur Bestimmung der Philosophie, GA.56/57. 2. ed. Frankfurt a. M.: V. Klostermann, 1987, p. 70

${ }^{18}$ Ahora bien, cuáles son las estructuras de la vivencia interrogativa auténticamente ejecutada, es un problema que al parecer Heidegger no desarrolla en esta primera lección y que, por tanto, no encuentra lugar en este ensayo.

19 "Im Kathedersehen bin ich mit meinem vollen Ich dabei [...] es its aber kein Vorgang, sondern ein Ereignis (Nicht-Vorgang, im Frageerlebnis ein Rest von Ereignis).” HEIDEGGER, M. Zur Bestimmung der Philosophie, GA.56/57. 2. ed. Frankfurt a. M.: V. Klostermann, 1987, p. 75.
} 
sentido de las vivencias circumundanas, a saber, su tercer y último elemento estructural reconocido por el joven Heidegger en esta, su primera lección: la apropiación (Ereignis).

La apropiación. El rasgo apropiativo inherente a toda vivencia circumundana hace referencia a la necesaria y absoluta imbricación entre el yohistórico y la vivencia, es decir, entre lo vivido y el yo-histórico que lo vive. Este rasgo es el caracterizado a lo largo de la extensa cita anterior a través de adjetivos tales como consonancia, resonancia, imbricación, el ritmo propio de la vida. Sólo en consonancia con mi yo-histórico, sostiene Heidegger, mundean las vivencias circumundanas, esto es, significan inmediatamente para un yo irrepetible que se apropia de lo vivido. $Y$ este es exactamente el modo en que inmediatamente vivo las vivencias, el modo en que cotidianamente trascurren nuestras vidas. ¿Pero en qué consiste precisamente la estructura del sentido de la vivencia interrogativa, y cuál es su relación con las vivencias circumundanas? Esto no queda claramente resuelto en la primera lección de Heidegger. Faltaría aclarar en última instancia la articulación entre estas dos clases de vivencias, y si la negativa caracterización del sentido de la vivencia interrogativa - no ser pro-ceso, y no apelar al yo-histórico - corresponden al sentido de ésta vivencia interrogativa ¿hay algo? en particular, o son extensivas al propio situarse ante cualquier actitud interrogativa, actitud tal vez propia del quehacer científico y filosófico. Por eso a propósito de la compleja relación entre las vivencias circumundanas y la actitud teorética Heidegger señala que:

El problema de la realidad y de la objetividad conduce a estas cuestiones básicas. Sería atrevido pretender resolver hoy [este problema] que apenas ha sido visto, donde todavía no se han descubierto los elementos primarios de su fundación [...] Tampoco para nosotros debe persistir la presunción de esclarecer el problema de la esencia y de la génesis significativa de lo teorético en sus líneas fundamentales. Más bien se trata simplemente de hacer visible el problema en el marco de nuestra actual problemática. ${ }^{20}$

\footnotetext{
20 "Das Problem der Realität und Objektivität führt auf ein prinzipielles. Es wäre vermessen, es heute schon lösen zu wollen, wo man es kaum gesehen hat, wo die primären Elemente seiner Fundierung noch nicht einmal entdeckt sind [...] Auch für uns soll nicht die Anmaßung bestehen, das Problem von Wesen und der sinnhaften Genesis des Theoretischen auch nur in seinen Grundlinien aufzuhellen. Vielmehr kann es sich nur darum handeln, das Problema innerhalb des Umkreises unserer bisherigen Problematik sichtbar zu machen." HEIDEGGER, M. Zur Bestimmung der Philosophie, GA.56/57. 2. ed. Frankfurt a. M.: V. Klostermann, 1987, p. 88.
} 
CÁCERES, Jorge Espinoza.Two Possible Directions of the Interrogative Experience Is There Something? In the Young Heidegger. Trans/Form/Ação, Marília, v. 37, n. 2, p. 219232, Maio/Ago., 2014.

\begin{abstract}
This article attempts two tasks. First, we highlight daily experience in its immediacy and gain an understanding of it through the first lecture of the young Heidegger. Second, based on this understanding, we clarify what we consider a confusing thematization in this lecture of the interrogative experience Is there something? In answering these questions we consider three distinct moments: the interrogative experience, the environmental experience, and a comparison of the different structural elements of both experiences. Finally, based on an understanding of these different points, we offer an interpretation of the two possible executive directions of the interrogative experience Is there something?
\end{abstract}

KEY WORDS: Young Heidegger. Environmental experience. Interrogative experience.

\title{
REFERENCIAS
}

DE LARA, F. Fenomenología del ser posible: la filosofía según el joven Heidegger. In: CARDONA, F. (Ed.). Heidegger: el testimonio del pensar. Bogotá: Javeriana, 2007, p. 27-47.

DE LARA, F. Phänomenologie der Möglichkeit: Grundzüge der Philosophie Heideggers 1919/1923. Freiburg: Karl Alber, 2008.

GREISCH, J. L'abre de vie et lábre du savoir: le chemin phénoménologique de l’herméneutique heideggérienne (1919-1923). Paris: du Cerf, 2000.

HEIDEGGER, M. Zur Bestimmung der Philosophie, GA.56/57. 2. ed. Frankfurt a. M.: V. Klostermann, 1987.

. Grundprobleme der Phänomenologie (1919/1920), GA 58. Frankfurt a. M.: V. Klostermann, 1993.

2005.

. La idea de la filosofía y el problema de la concepción del mundo. Barcelona: Herder,

KISIEL, T. The genesis of Heidegger's being and time. Berkeley, CA: University of California Press, 1993.

; VAN BUREN, J. Reading Heidegger from the start: essays in his earliest thought. New York: Suny, 1994.

MARTINEZ MATIAS, P. La dinámica de la facticidad. Revista de Filosofía, Madrid, v. 30 n. 2, p. 89-118, 2005.

RODRIGUEZ, R. La transformación hermenéutica de la fenomenología. Madrid: Tecnos, 1997.

Recebido em: 21/11/13

Aceito em: 05/01/14 